\title{
Characterization of Mexican Isolates of Colletotrichum lindemuthianum by Using Differential Cultivars and Molecular Markers
}

\author{
Mario González, Raul Rodríguez, Maria Elena Zavala, Juan L. Jacobo, Fernando Hernández, \\ Jorge Acosta, Octavio Martínez, and June Simpson
}

First, second, third, fifth, seventh, and eighth authors: Department of Genetic Engineering, CINVESTAV, Unidad Irapuato, Apdo. Postal 629, Irapuato, Guanajuato, Mexico; fourth author: The Instituto Nacional de Investigaciones Forestales, Agrícolas y Pecuarias. (INIFAP), Campo Experimental Valle del Guadiana, Apdo. Postal 186, Durango, Dgo., Mexico; and sixth author: INIFAP, Campo Experimental Valle de Mexico, Chapingo, Edo. de Mexico, Mexico.

Accepted for publication 3 December 1997.

\begin{abstract}
González, M., Rodríguez, R., Zavala, M. E., Jacobo, J. L., Hernández, F., Acosta, J., Martínez, O., and Simpson, J. 1998. Characterization of Mexican isolates of Colletotrichum lindemuthianum by using differential cultivars and molecular markers. Phytopathology 88:292-299.

Differential cultivars and molecular markers were used to analyze 59 isolates of the bean anthracnose pathogen, Colletotrichum lindemuthianum, from different regions of Mexico. Ten distinct races were determined, three of which had not been reported previously in Mexico. Isolates were found to infect only a narrow range of the differential

A comparison of random amplified polymorphic DNA and amplified fragment length polymorphism (AFLP) analyses was carried out on a subset of the fungal isolates. Determination of genetic distances based on AFLP data and production of a dendrogram demonstrated two levels of association: i) isolates classified into two major groups according to the type of cultivar or system of cultivation from which they originated, and ii) isolates could be classified into smaller subgroups generally associated with the geographic location from which they were obtained. Bootstrap analysis and determination of confidence intervals showed these geographic groupings to be extremely robust.
\end{abstract} cultivars used and were restricted to cultivars of Middle American origin.
Anthracnose disease of common bean (Phaseolus vulgaris L.), caused by the fungal pathogen Colletotrichum lindemuthianum (Sacc. \& Magnus) Lams.-Scrib., can be devastating when climatic conditions favor the pathogen and when large areas sown with a single bean cultivar are challenged by new pathotypes. Although good agricultural practices and clean seed can greatly reduce the spread of the pathogen, these measures are not always feasible, especially in developing countries, for which the best strategy is to produce resistant germ plasm. In order to implement effective breeding programs, it is necessary to have an idea of the prevalence and distribution of pathotypes of the fungus within a given area.

Since 1956 (22,23), several investigators have reported the presence of different pathotypes or races of $C$. lindemuthianum in Mexico, and to date, approximately 30 different races have been identified (4). These studies have been sporadic, and no systematic characterization of $C$. lindemuthianum races on a national scale has been carried out. Moreover, since different sets of differential cultivars were employed in each study, results are not directly comparable between the different reports.

To overcome this problem, a group of 12 differential cultivars and a universal system of nomenclature has been proposed by the Centro Internacional de Agricultura Tropical (CIAT) (11). Adoption of this system by investigators working with $C$. lindemuthianum allows comparison and compilation of data from different groups.

Corresponding author: J. Simpson; E-mail: jsimpson@irapuato.ira.cinvestav.mx

Publication no. P-1998-0202-01R

(C) 1998 The American Phytopathological Society
Although differential cultivars are useful in determining races or pathotypes of plant pathogens, classification of disease severity is often subjective, depending on the experience of the investigator. Mixed or segregating germ plasm and different growth and infection conditions can also exacerbate the problem. A possible solution is to combine data from differential cultivars with DNAbased molecular marker analysis.

Our interest is to study the variability of $C$. lindemuthianum populations in Mexico by combining analyses involving differential cultivars with molecular marker analysis. Isolates of the pathogen were obtained from two geographically distinct regions of Mexico in which commercial bean cultivars are grown under very different conditions. The objectives of the study were to i) determine the variability of the pathogen in terms of races or pathotypes as defined by inoculation of differential cultivars; ii) compare the efficiency of random amplified polymorphic DNA (RAPD) and amplified fragment length polymorphism (AFLP) markers for classifying $C$. lindemuthianum isolates, iii) analyze the variability of the pathogen at the genotype level, and iv) compare the variability in pathotypes with that determined by molecular marker techniques.

This is the first large-scale study of Mexican C. lindemuthianum isolates from commercially grown bean cultivars, although recent studies have included isolates from wild $P$. vulgaris populations in Mexico (15).

\section{MATERIALS AND METHODS}

Collection of isolates. Two contrasting geographical regions were chosen for this study: i) the region encompassing the northern states of Chihuahua, Durango, and Zacatecas, which constitute the main bean-growing areas on a commercial scale in Mexico 
and where mainly bush-type bean cultivars are grown in large, open fields, and ii) the states of Jalisco and Michoacán, where climbing-type cultivars are grown in small plots in combination with maize.

Samples were obtained from the five states during September through November from 1992 to 1996. In total, 22 monospore cultures were obtained from Chihuahua, 7 from Zacatecas, 9 from Durango, 15 from Jalisco, and 6 from Michoacán (Fig. 1).

Fungal isolates. Samples of $C$. lindemuthianum were obtained from leaves or pods of naturally infected bean plants found in the field. Pieces of infected plant tissue were placed on acidified potato dextrose agar (PDA) (Difco, Detroit, MI), and colonies showing growth and morphology typical of $C$. lindemuthianum were transferred to fresh acidified PDA, where they were maintained until sporulation was achieved. In cases where cultures failed to sporulate on PDA, samples were grown on sterilized Haricot type bean pods to induce sporulation (4). A suspension of spores was prepared from these cultures and dispersed on fresh acidified PDA. After 24 to $48 \mathrm{~h}$, individual germinated spores were transferred to fresh acidified medium. A colony produced from a single spore was maintained as a pure isolate for infection of differential cultivars and genotype analysis. Replicate cultures were stored in agar and mineral oil.

Differential cultivars. To distinguish the races of different $C$. lindemuthianum isolates, the set of differential cultivars proposed by CIAT (11) was used. The set consists of 12 cultivars, each with a designated binary number. The cultivars and their binary numbers are Michelite (1), Michigan Dark Red Kidney (2), Perry Marrow (4), Cornell 49242 (8), Widusa (16), Kaboon (32), Mexico 222 (64), PI 207262 (128), To (256), Tu (512), AB136 (1024), and G2333 (2048). The number or race designation given to an isolate is determined by the cultivars of the differential set that are infected by that isolate. The sum of the numbers assigned to each infected cultivar is the race number; e.g., an isolate infecting the cultivars Perry Marrow, Widusa, and Mexico 222 would be designated race 84 .

Inoculation of differential cultivars. Spores from each isolate were suspended at a concentration of $1.5 \times 10^{6} / \mathrm{ml}$ and sprayed onto the undersides of 7- to 10-day-old bean plants. Three plants of each cultivar were inoculated in each experiment, and the whole experiment was repeated at least twice. Inoculated plants were grown under $95 \%$ humidity for 8 to 10 days and then evaluated for symptoms. Symptoms were evaluated on a five-level scale as described by Garrido et al. (4), where 0 to $2=$ resistant and 3 to 4 = susceptible.

DNA manipulation and analysis. DNA of $C$. lindemuthianum was obtained essentially by the method of Raeder and Broda (14). Ten milliliters of potato dextrose broth (Difco) was inoculated with a suspension of spores (approximately $5 \times 10^{6} / \mathrm{ml}$ ) and incubated at 25 to $28^{\circ} \mathrm{C}$ for 24 to $48 \mathrm{~h}$. Mycelia were then harvested by filtration through Whatman no. 1 paper, washed once in TES buffer (100 mM Tris- $\mathrm{HCl}, \mathrm{pH} 8,150 \mathrm{mM} \mathrm{NaCl}$, and $5 \mathrm{mM}$ EDTA), and lyophilized.

Samples were then frozen in liquid nitrogen and ground to a fine powder with a mortar and pestle. Extraction buffer $(200 \mathrm{mM}$ Tris-HCl, $\mathrm{pH}$ 8.5, $250 \mathrm{mM} \mathrm{NaCl}, 25 \mathrm{mM}$ EDTA, and 0.5\% sodium dodecyl sulfate) was added, and after mixing, samples were extracted once with phenol-chloroform and centrifuged at 13,000 $\mathrm{rpm}$ in an Eppendorf microcentrifuge for $30 \mathrm{~min}$. The supernatant was extracted once with chloroform and then precipitated with isopropanol. The resuspended pellet was treated with RNase, and the samples were again extracted with phenol-chloroform, precipitated, washed in $70 \%$ ethanol, and resuspended in sterile distilled water. DNA was quantified visually in agarose gels.

RAPD analysis. RAPD reactions $(20,21)$ were carried out with 10-base oligonucleotide primers (Operon Technology, Alameda, CA) (Table 1). The reaction mixture consisted of Taq DNA polymerase buffer $\left(10 \times 100 \mathrm{mM}\right.$ Tris-HCl, $\mathrm{pH} 8,15 \mathrm{mM} \mathrm{MgCl}_{2}$,

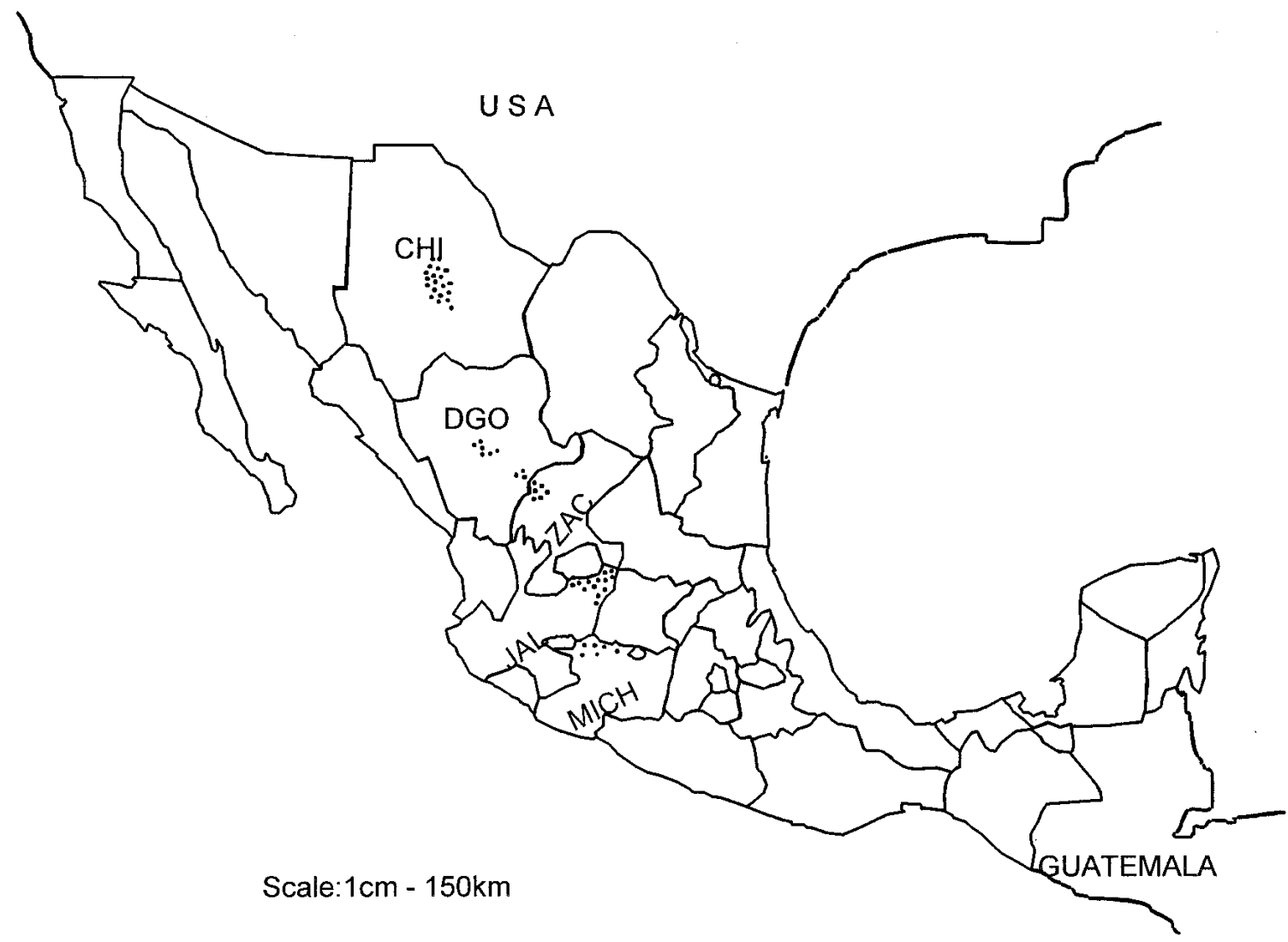

Fig. 1. Approximate locations in Mexico at which Colletotrichum lindemuthianum isolates were collected. $\mathrm{CHI}=\mathrm{Chihuahua}, \mathrm{ZAC}=\mathrm{Zacatecas}, \mathrm{DGO}=$ Durango, JAL $=$ Jalisco, and MICH $=$ Michoacán . 
and $500 \mathrm{mM} \mathrm{KCl}$ ), $400 \mu \mathrm{M}$ of each dNTP, $0.2 \mathrm{mM}$ oligonucleotide primer, $15 \mathrm{ng}$ of genomic DNA from $C$. lindemuthianum, and 1 unit of Taq polymerase (Boehringer Mannheim, Indianapolis, IN) in a final volume of $25 \mu \mathrm{l}$. Amplification was carried out in a 9600 thermocycler (Perkin Elmer, Norwalk, CT) programmed for $5 \mathrm{~min}$ at $95^{\circ} \mathrm{C}, 45$ cycles of $1 \mathrm{~min}$ at $95^{\circ} \mathrm{C}, 1 \mathrm{~min}$ at $39^{\circ} \mathrm{C}$, and $1.5 \mathrm{~min}$ at $72^{\circ} \mathrm{C}$ followed by $7 \mathrm{~min}$ at $72^{\circ} \mathrm{C}$. Amplification products were separated on $1.4 \%$ agarose gels and observed under UV light after they were stained with ethidium bromide.

AFLP analysis. The AFLP protocol used was similar to that reported by Vos et al. (19), with the exception that two rather than three selective nucleotides were used in order to generate an adequate number of bands for analysis.

The AFLP protocol consists in digestion of total fungal genomic DNA with the restriction enzymes EcoRI and MseI. Adapter molecules specific for the restriction fragment ends were then ligated to the mixture of restriction fragments. The adapter molecules and nucleotides adjacent to the site of ligation serve as a template for the annealing of specific oligonucleotide primers used for polymerase chain reaction (PCR) amplification reactions. Each fragment may differ internally in the nucleotides immediately adjacent to the restriction sites, and this property is the

TABLE 1. Summary of RAPD and AFLP primers used, number of bands obtained, and number of polymorphic bands obtained in this study ${ }^{\mathrm{a}}$

\begin{tabular}{lcc}
\hline & $\begin{array}{c}\text { Amplified } \\
\text { bands }\end{array}$ & $\begin{array}{c}\text { Polymorphic } \\
\text { bands }\end{array}$ \\
\hline Oligonucleotide (RAPD) & & \\
OPD 01 ACCGCGAAGG & 9 & 9 \\
OPD 02 GGACCCAACC & 10 & 10 \\
OPD 03 GTCGCCGTCA & 8 & 8 \\
OPD 05 TGAGCGGACA & 6 & 6 \\
OPD 07 TTGGCACGGG & 6 & 6 \\
OPD 08 GTGTGCCCCA & 4 & 4 \\
OPD 11 AGCGCCATTG & 3 & 3 \\
OPD 13 GGGGTGACGA & 6 & 6 \\
OPD 18 GAGAGCCAAC & 4 & 4 \\
OPD 20 ACCCGGTCAC & 6 & 6 \\
Total & 62 & 62 \\
Combination (AFLP) & & \\
AG/AG & 53 & 41 \\
AC/AC & 63 & 55 \\
AT/AT & 51 & 39 \\
AA/AA & 63 & 48 \\
Total & 230 & 183 \\
\hline
\end{tabular}

${ }^{\mathrm{a}} \mathrm{RAPD}=$ random amplified polymorphic DNA, and AFLP $=$ amplified fragment length polymorphism.

TABLE 2. Races of Colletotrichum lindemuthianum identified in Mexico, infection of differential cultivars, and number of isolates analyzed in this study

\begin{tabular}{lllr}
\hline State & $\begin{array}{l}\text { Races } \\
\text { identified }\end{array}$ & Differential cultivars infected & $\begin{array}{c}\text { Isolates } \\
\text { (no.) }\end{array}$ \\
\hline Chihuahua & 448 & Mexico 222, PI207262, To & 22 \\
Durango & 256 & To & 6 \\
& 448 & Mexico 222, PI207262, To & 2 \\
Zacatecas & 1088 & Mexico 222, AB136 & 1 \\
& 256 & To & 3 \\
& 320 & Mexico 222, To & 1 \\
& 448 & Mexico 222, PI207262, To & 1 \\
Jalisco & 1472 & Mexico 222, PI207262, To, AB136 & 2 \\
& 0 & . & 4 \\
Michoacan & 384 & PI207262, To & 5 \\
& 392 & Cornell 49242, PI207262, To & 6 \\
& 8 & $\ldots$ & 1 \\
& 256 & Cornell 49242 & 1 \\
& 264 & Co & 1 \\
& 392 & Cornell 49242, To & 2 \\
\hline
\end{tabular}

basis of the selective amplification characteristic of the AFLP method. An initial amplification was carried out with one selective nucleotide, in this case, A; therefore, only a subset of the total number of restriction fragments was amplified (those having an A adjacent to the restriction site).

Oligonucleotide primers used for the preamplification step were $E c o$ RI (EcoRI+A) 5'-AGACTGCGTACCAATTC/A-3' and MseI (MseI+A) 5'-GACGATGAGTCCTGAGTAA/A-3'. The preamplification step was followed by a second selective amplification step with two selective nucleotides, A plus A,T,G or C. The specific region targeted by each primer is therefore a seven-nucleotide sequence in the case of EcoRI and a five-nucleotide sequence in the case of MseI. For example, the nucleotides shown in bold above plus one extra nucleotide as shown in Table 1 constitute the specific sequence. Only a fraction of each preamplification product was thus amplified in the second reaction. The EcoRI primer used in the second amplification reaction was radioactively labeled

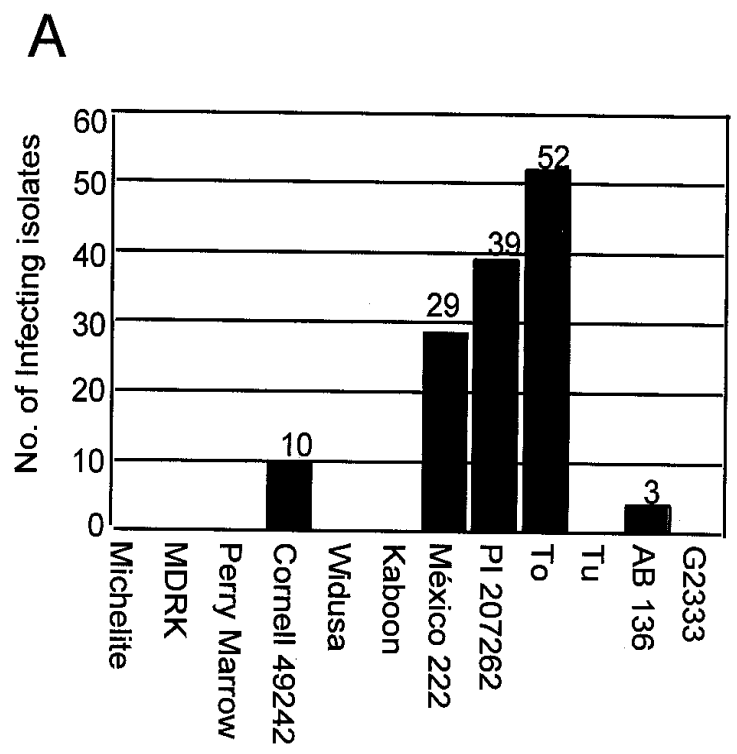

Differential cultivars

B

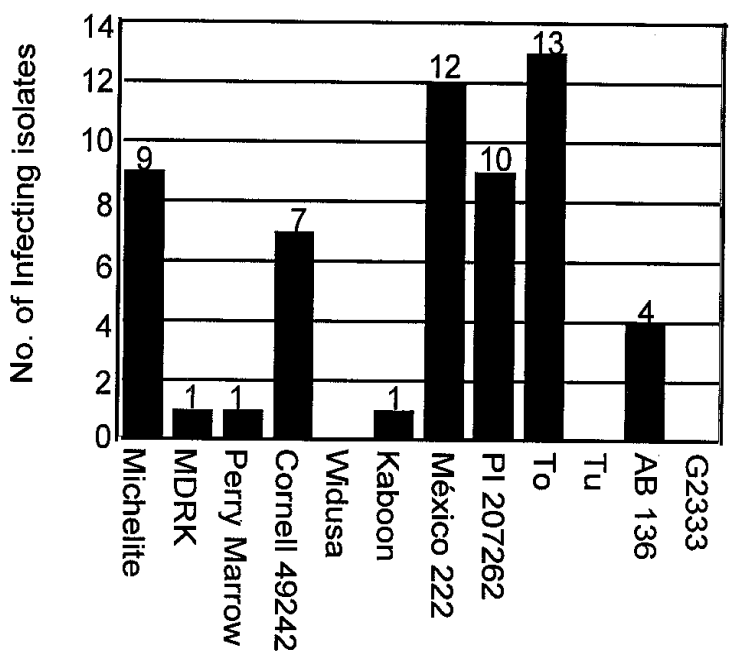

\section{Differential cultivars}

Fig. 2. Number of isolates infecting each differential cultivar. A, Data from the present study. B, Data compiled from previous studies of Colletotrichum lindemuthianum isolates in Mexico in which the CIAT set of differential cultivars was used. 
by using T4 kinase, and the products of the second amplification reaction were visualized after electrophoresis on a polyacrylamide sequencing gel and autoradiography.

Data analysis. Bands observed by either AFLP or RAPD analysis were assigned a number in relation to their migration within the gel. Bands with the highest molecular weight were assigned number 1 and so on in ascending order until the band of lowest molecular weight was assigned. It was assumed that bands of the same molecular weight in different individuals were identical. For each individual, the presence or absence of each band was determined and designated 1 , present or 0 , absent. The genetic distance between individuals was estimated by using the simple matching coefficient $(16,17)$. The distance matrix generated was then used to produce a dendrogram by the unweighted pair group method with arithmetic averages (UPGMA) by using SAS 6.08 for Windows and S-plus 4.0 for Windows software (SAS Institute, Cary, NC).

To evaluate the relationship between the genetic similarities estimated from RAPD data with those obtained from AFLP data, the Pearson's product moment correlation coefficient, $r$, was calculated. In addition to the correlation analysis with the complete AFLP data set, four independent samples of the AFLP data set were taken, and correlations between each of these samples and the RAPD data were obtained. Correlations between each of the AFLP data sets were also obtained. This was done to compare the correlation between the two marker systems (RAPD and AFLP) with the baseline correlation expected from independent samples within the same marker system.

In order to determine the significance of the grouping determined visually in the extended AFLP analysis of samples from five states, the original distance matrix was reduced to a matrix containing the distances between groups by taking the average distance between the individuals in each group. The UPGMA method was then performed to produce a summarized dendro- gram. To determine the robustness of this summarized dendrogram, a bootstrap resampling method was performed. For each bootstrap replication, the data matrix was resampled and the distance matrix reconstructed and reduced as described above. The topology of the resulting dendrogram was then compared with the topology of the dendrogram produced from the original data. A total of 2,000 bootstrap replications were performed, obtaining bootstrap confidence intervals (1) of $95 \%$ for the distances between groups. The first and third quartile of distances within each group were obtained from the original distance matrix between individual isolates.

\section{RESULTS}

Identification of races of $\boldsymbol{C}$. lindemuthianum. A summary of the races found in each state and the number of isolates corresponding to each race are presented in Table 2. From the 59 isolates analyzed, a total of 10 pathotypes were determined. Races 320 and 1472 were exclusive to Zacatecas, race 1088 to Durango, race 384 to Jalisco, and races 8 and 264 to Michoacán.

Infection of individual differential cultivars. Race numbers give an indication of the variability of the pathogen in terms of pathogenicity. However, the occurrence of many distinct races does not directly imply a wide range of resistance and avirulence interactions. To obtain more detailed information on these interactions, the number of isolates infecting each individual cultivar was determined (Fig. 2A). Only five of the CIAT differential cultivars were found to be infected by our $C$. lindemuthianum isolates; Mexico 222, PI207262, and To were most commonly infected.

Compilation of Mexican races of $C$. lindemuthianum identified by using CIAT differentials. In order to determine whether the pattern of infection of the differential cultivars by Mexican $C$. lindemuthianum isolates is a general phenomenon observed in
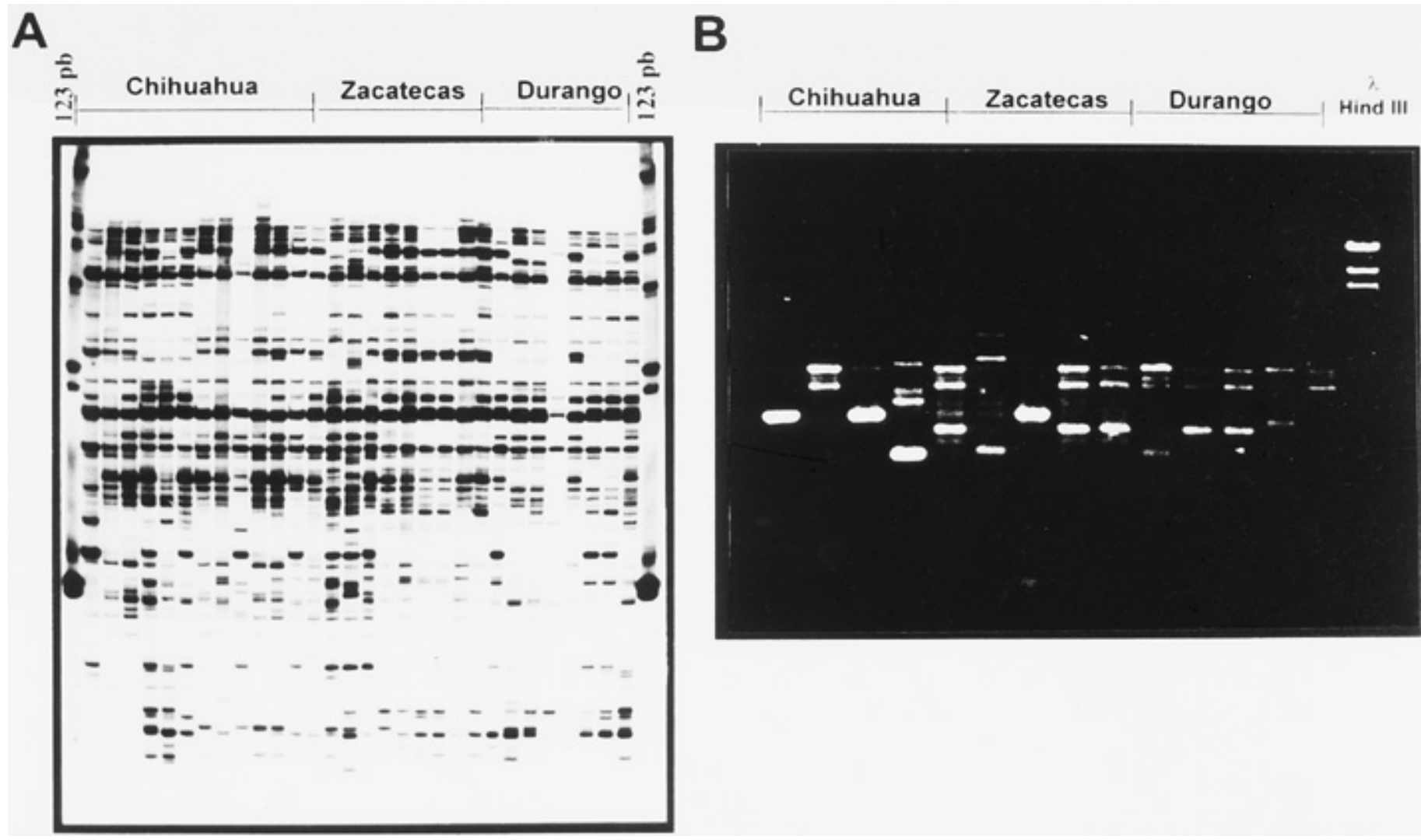

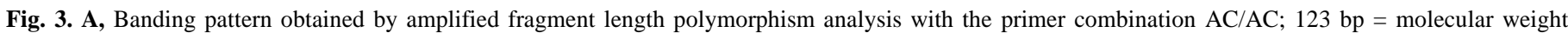
ladders. B, Banding pattern obtained by random amplified polymorphic DNA analysis with primer OPD07; $\lambda$ HindIII $=$ molecular weight marker. 
other studies, a comparison was made of the infection patterns of all races (26 in total) reported in Mexico based on the CIAT differential set (Fig. 2B).

These compiled results indicate that the cultivars most frequently found to be susceptible in other studies are Mexico 222, PI207262, To, Cornell 49242, AB136, and Michelite. The differential cultivars of Andean origin (Michigan Dark Red Kidney, Perry Marrow, and Kaboon) were infected only once. Of 129 Mexican isolates characterized by the CIAT system, none were capable of infecting the cultivars Widusa, To, and G2333.

RAPD analysis. The 38 monospore cultures of isolates from Chihuahua, Zacatecas, and Durango were analyzed with 10 polymorphic oligonucleotide primers. Of the 36 primers tested for polymorphism with the 38 isolates, 26 showed polymorphism, and the 10 most polymorphic primers were chosen to carry out the analysis. The primers used, total numbers of bands, and the numbers of polymorphic bands obtained for these isolates are summarized in Table 1. A typical example of the banding patterns obtained with RAPD is shown in Figure 3B. Information on banding patterns for all primers was used to determine genetic distances between isolates and to construct a dendrogram (Fig. 4A). It was found that all individual isolates can be distinguished by RAPD analysis. The tendency was to group isolates in relation to their geographical locations, and no direct correlation between molecular genotype and pathotype was observed.
In order to determine the robustness of the estimated dendrogram, 2,000 bootstrap samples were taken. From the 95\% confidence intervals for the similarities (distances) between isolates, it was established that the topology was not robust; different bootstrap samples gave very different trees (data not shown).

AFLP analysis. The same monospore cultures analyzed with RAPD markers were also analyzed with four AFLP primer combinations. A summary of the primer combinations, numbers of bands observed, and numbers of polymorphic bands is presented in Table 1. A typical banding pattern obtained by using AFLPs is shown in Figure 3A. The total number of bands obtained with four AFLP combinations is almost fourfold higher than that obtained with 10 RAPD primers, and the number of polymorphic bands is almost threefold higher. AFLP data was used to determine genetic distances and construct a dendrogram (Fig. 4B). In contrast to the RAPD analysis, the AFLP analysis shows a very clear association between geographical distribution and the groups obtained by analysis of genetic distances. No direct association between genotype and pathotype was observed.

Correlation of RAPD and AFLP results. There is a marked difference in the distribution of samples and topology of the dendrograms obtained by using RAPD and AFLP markers. In order to assess the relationship between the estimations of genetic similarities obtained with RAPD and AFLP markers, a correlation analysis was performed. The Pearson's product moment correla-

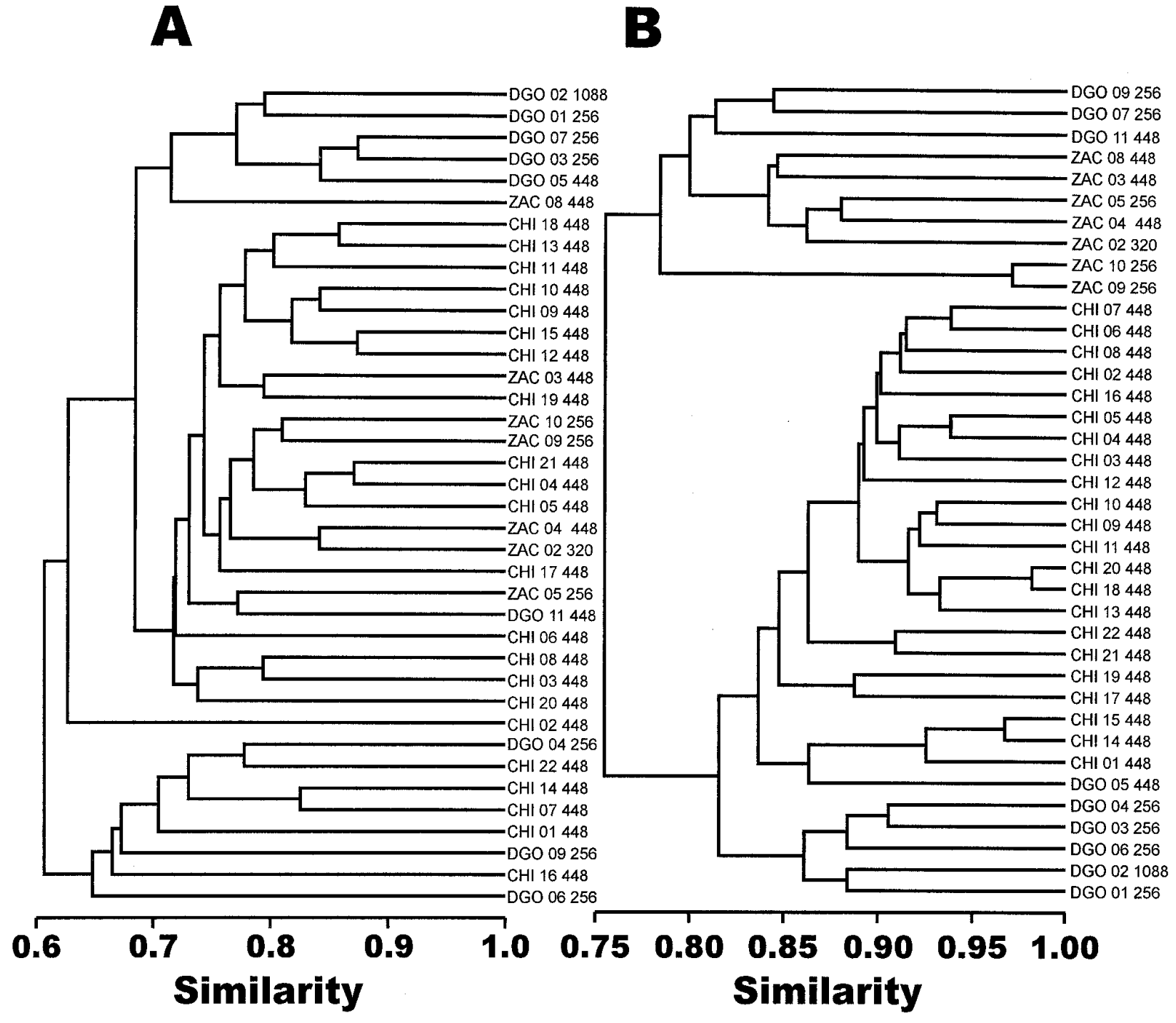

Fig. 4. Comparison of dendrograms obtained by $\mathbf{A}$, random amplified polymorphic DNA and $\mathbf{B}$, amplified fragment length polymorphism analyses. CHI $=$ Chihuahua, $\mathrm{DGO}=$ Durango, and $\mathrm{ZAC}=$ Zacatecas. Numbers to the right denote pathotypes. 
tion estimated between genetic similarities obtained from AFLP and RAPD analyses was $r=0.15$. To determine whether this low value of $r$ was produced by chance because of the relatively low number of bands analyzed by the RAPD method, a correlation analysis between the similarities obtained from the RAPD data and those obtained for subsets of the AFLP data was performed. Correlations between the subsets of AFLP data were also performed. Four independent subsets of AFLP bands were used in the analysis. Figure 5 presents the scatter diagrams comparing genetic similarity measured from the RAPD data and each one of the four AFLP subsets (AFLP-S1 to AFLP-S4). The least squares regression line between the similarities and the correlation estimated between these similarities are shown. Correlations between similarities obtained from RAPD data and all of the subsets of data obtained from AFLPs are low, ranging from a minimum of $r=$ 0.04 to a maximum of $r=0.20$, with an average of $r=0.13$, close to the $r=0.15$ obtained with the complete AFLP data set. In contrast, there is a clear linear relationship between the similarities estimated from the four independent AFLP samples, with minimum $r=0.55$, maximum $r=0.73$, and an average of $r=0.61$.

Comparison of $C$. lindemuthianum populations in five Mexican states by using AFLPs. The results presented above show that the AFLP technique is more efficient in terms of the number of analyses necessary to rapidly obtain sufficient data and that different subsets of data are highly correlated. Therefore, an extended analysis of $C$. lindemuthianum isolates from two additional Mexican states, Michoacán and Jalisco, was carried out by using AFLPs (Fig. 6). The grouping of isolates in relation to geographical distribution was maintained. In addition, isolates from the two main regions, Chihuahua-Zacatecas-Durango and MichoacánJalisco, were clearly separated from each other (A and B in Figure 6). Four subgroups based on visual analysis of the dendrograms and the relation to the geographic origin of the isolates could be determined and were designated $\mathrm{a} 1, \mathrm{a} 2, \mathrm{~b} 1$, and $\mathrm{b} 2$. In order to determine the robustness of these groups, statistical analyses involving 2,000 bootstrap samples of the data was carried out (Fig. 7). The topology of the dendrogram was the same as that in

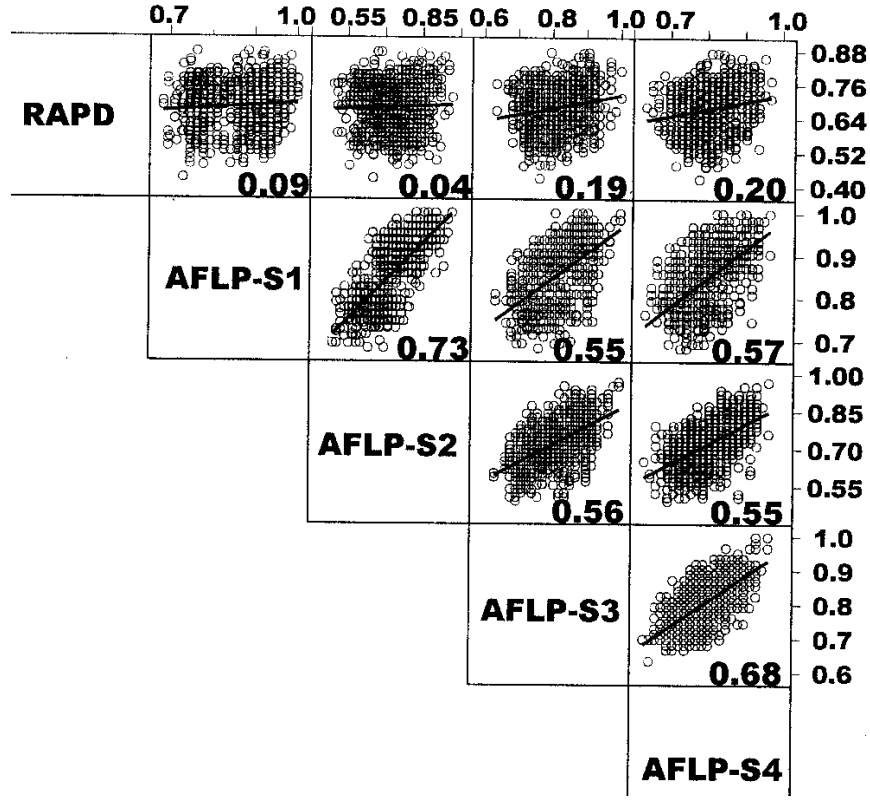

Fig. 5. Correlations between genetic similarities determined from amplified fragment length polymorphism (AFLP) and random amplified polymorphic DNA (RAPD) data. Open circles represent the genetic similarities between all pairwise combinations of the 38 isolates, estimated from 62 RAPD bands and four independent samples of 62 AFLP bands. The correlation coefficient, $r$, is shown in the bottom right-hand corner of each box. Lines represent the least squares regression between the similarities.
Figure 7 for all 2,000 bootstrap samples, suggesting that the geographical grouping was extremely robust. In addition, the $95 \%$ confidence intervals also supported the division into four groups, since the intervals were narrow and no overlap in intervals was observed. Isolates from Jalisco and Michoacán were clearly distinguished, both from each other and from the isolates of the other three states. Although there was strong evidence to separate groups a1 and a2, these groups are not as distant as groups b1 and b2.

\section{DISCUSSION}

Ten distinct pathotypes or races were determined in the 59 isolates examined in this study. Three of these, races 8, 1472, and 1088, are reported for the first time in Mexico. In Chihuahua, only race 448 was found, whereas four races were found in Zacatecas, three in Durango and Jalisco, and five in Michoacán. Only one race, 256, was common to both geographic regions.

The differences in the pathogen populations between the two regions probably reflect the differences in germ plasm used and the agricultural practices employed in each region. The bean cultivars grown in Chihuahua, Zacatecas, and Durango are chosen to meet the needs of the market. Bush-type cultivars are grown in monoculture and mechanically harvested. In contrast, in Jalisco and Michoacán, a mixture of climbing-type cultivars and land races are grown in combination with maize. It is also interesting to note the variability of the pathogen in the Michoacán region, where in a group of only six isolates, five distinct pathotypes were

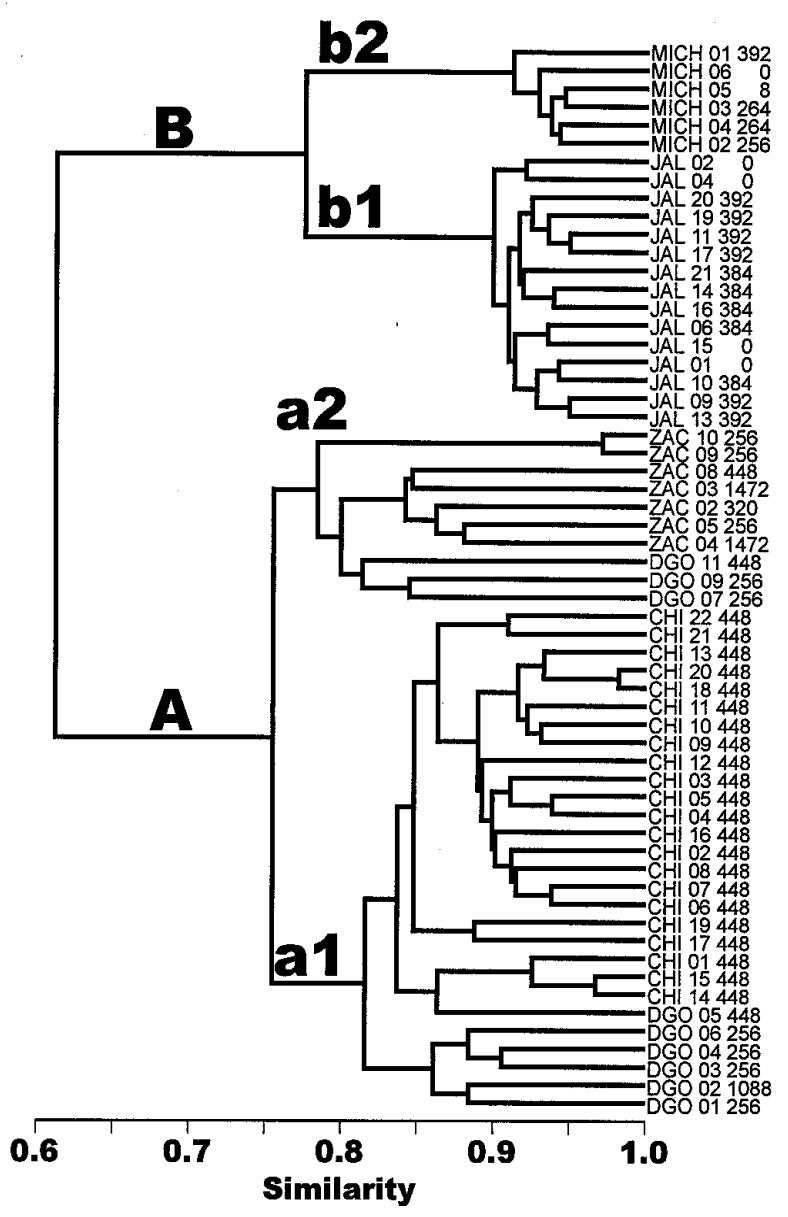

Fig. 6. Dendrogram produced by using amplified fragment length polymorphism data of isolates from five Mexican states. A and B denote the two main groups determined; a1, a2, b1, and b2 are the subgroups. $\mathrm{CHI}=\mathrm{Chi}-$ huahua, $\mathrm{DGO}=$ Durango, $\mathrm{ZAC}=$ Zacatecas, $\mathrm{MICH}=$ Michoacán, and JAL = Jalisco. Numbers to the right denote pathotypes. 
found, whereas in Chihuahua, where one main type of cultivar has been grown for many years, only one pathotype was identified. In the Michoacán region, the abundance of wild $P$. vulgaris, often growing in close proximity to the cultivated forms, may also lead to an increase in the pathogen diversity in this region.

The 10 distinct races identified in this study infect only five of the 12 CIAT differential cultivars. With the exception of race 0 , which does not infect any of the differential cultivars, and one isolate from Michoacán classified as race 8, all isolates infected at least one of the three differential cultivars Mexico 222, PI207262, and To. Of the 59 isolates, 11 infected two additional cultivars, Cornell 49242 and AB136.

These results correlate well with those of other studies conducted on Mexican C. lindemuthianum isolates. A compilation of data from other reports in which the CIAT differential set was used shows that only four of 26 races did not infect either Mexico 222, PI207262, or To. Three of the four races that did not infect Mexico 222, PI207262, or To did infect Cornell 49242 or AB136. Only one isolate failed to infect any of the five most commonly infected cultivars. Interestingly, the three most frequently infected cultivars are of Mexican origin. Mexico 222 and To each have a characterized anthracnose resistance gene, Mex 1 a (Co 3) and Mex 2 (Co 4) (3), respectively. The genetic basis of resistance in PI207262 is unknown but is expected to be different from that of either Mexico 222 or To, since isolates specifically infecting PI207262 have been observed $(13,15)$.

The preferential infection of the three cultivars probably reflects the adaptation of the pathogen within Mexico to overcome resistance genes to which it is most commonly exposed. This is probably also true of AB136, which has resistance gene Co 6 (23). In the case of Cornell 49242 (which is derived from Venezuelan germ plasm and contains the Are [Co 2] resistance gene) (10) and Michelite (resistance gene as yet unidentified), adaptation to resistance by the pathogen may be the result of the widespread use of this germ plasm in Mexico to provide anthracnose resistance.

Two main centers of domestication of $P$. vulgaris have been determined, one in Middle America (Mexico and Central America) and one in the Andean region (South America) (7). In the differential cultivar set, three cultivars are of Andean origin, Perry

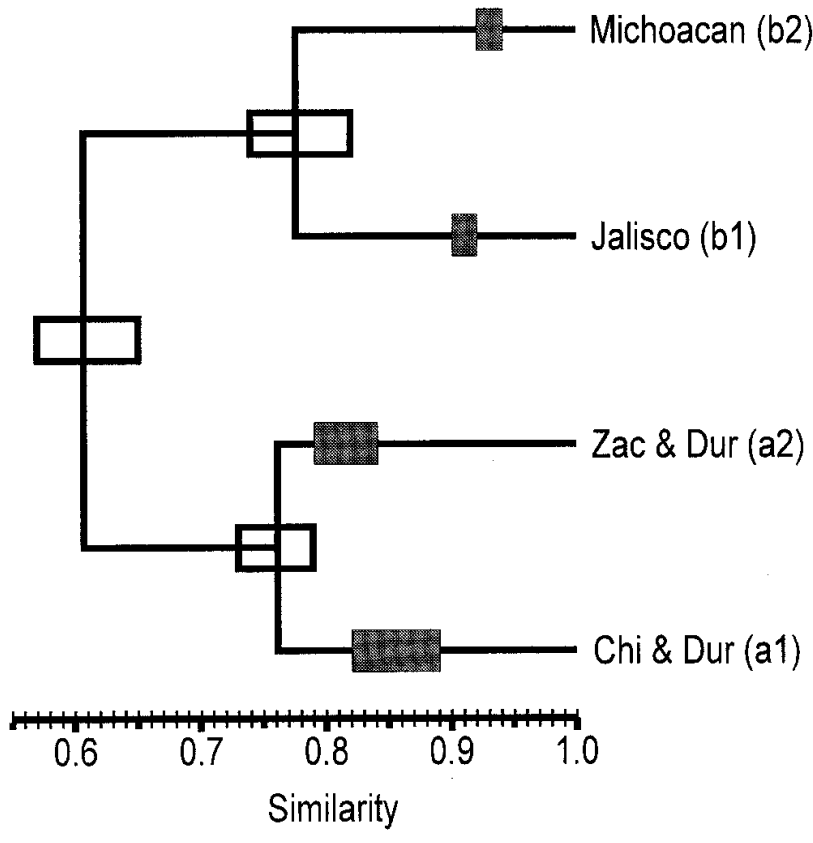

Fig. 7. Results of bootstrap analysis. a1, a2, b1, and b2 are subgroups of main groups A and B, respectively. Open boxes represent $95 \%$ confidence intervals at internodes; solid boxes represent the interquartile range of distances within each group.
Marrow, Michigan Dark Red Kidney, and Kaboon; all the others are of Middle American origin. None of the isolates analyzed in this survey infected any of the Andean cultivars. When the races previously reported in Mexico by using the CIAT differential set were analyzed, only two of 129 isolates infected Andean cultivars $(12,15)$, suggesting that races of $C$. lindemuthianum capable of infecting Andean germ plasm are rare in Mexico, whereas those capable of infecting germ plasm of Middle American and especially Mexican origin predominate.

None of the 129 isolates studied were capable of infecting the differential cultivars Widusa, Tu, or G2333. The genetic basis of resistance in Widusa is unknown, but Tu and G2333 both contain the resistance gene Mex 3 (Co 5) $(3,12,24)$, and G2333 also contains a second gene, Co $7(12,24)$. This information is important for breeders interested in developing anthracnose-resistant cultivars in Mexico, suggesting that the Mex 3 resistance gene may be particularly durable and that the three resistant cultivars and closely related lines in combination with lines of Andean origin may provide effective resistance to $C$. lindemuthianum in Mexico.

Molecular markers such as RAPD and microsatellites have proved extremely useful in the study of populations of microorganisms. Recent reports, however, have suggested that the AFLP technique is more efficient in rapidly generating genotype data for large numbers of individuals, including plants (5), bacteria (6), and fungi (9). The results presented here also demonstrate the efficiency of AFLP markers for studying $C$. lindemuthianum populations. Where 10 RAPD primers gave a total of 62 bands, four AFLP primer combinations gave 230 bands, almost a fourfold difference. Correlation analyses carried out between the two data sets showed a very low correlation between similarities obtained from RAPD data and those from AFLP data, while subsets of AFLP data showed high correlations. This may result from the fact that AFLP markers are more widely dispersed throughout the genome. Spooner et al. (18) suggested that increasing the number of bands analyzed with RAPD increases the reliability of the phenetic relationships determined. This also seems to be the case for AFLP, since when subsets of the AFLP data were used to generate dendrograms, the association with geographical origin was not supported as well as when the complete data set was used (data not shown). Analysis of a larger number of bands allows a more robust statistical analysis with a high probability that the dendrogram produced is representative of the population structure of the organism. This was confirmed by the bootstrap analysis of the AFLP data. In order to obtain similarly robust data with RAPD, many more oligonucleotide reactions would need to be used, increasing the time and cost of the analysis. Previous analyses of $C$. lindemuthianum isolates with RAPD have also failed to show direct association between haplotype patterns and geographic origin, even when isolates from distant regions were compared. Sicard et al. (15) showed that although Mexican isolates could be distinguished from isolates from Argentina and Ecuador, isolates from these last two countries could not be distinguished by RAPD haplotype alone. Fabre et al. (2) also reported the failure to distinguish between Latin American $C$. lindemuthianum isolates and isolates from Europe and Africa on the basis of RAPD haplotypes.

Although only 10 pathotypes were determined for the 59 isolates, a much higher diversity was observed at the genotype level, since all 59 isolates examined had unique AFLP and RAPD haplotypes. Statistical analysis strongly supports the division of the isolates into four haplotype groups. C. lindemuthianum is a deuteromycete for which no sexual stage has been observed under field conditions. It is expected, therefore, that natural populations of the pathogen will consist of clonal lineages produced by asexual reproduction. The four clearly defined groups and the close relationship among individuals within a group suggest that the haplotype groups determined by the AFLP analysis may represent distinct genetic lineages of the pathogen, as has previously been suggested for Pyricularia oryzae (8). 
As has been reported in other host-pathogen systems (25), a perfect correlation between genotype and pathotype is seldom observed. However, a correlation between the defined lineages and both cultivar type and pathotype can be established. As mentioned previously, in the region encompassing Chihuahua, Zacatecas, and Durango, bush-type cultivars are preferred, whereas in Jalisco and Michoacán, climbing types are preferred. This also correlates with the two main $C$. lindemuthianum groups observed. In this study, all isolates from bush-type cultivars are found in group A and those from climbing types are found in group $\mathrm{B}$. The subgroups a1, a2, b1, and b2 may correlate further to specific cultivars used within each region, but we currently do not have sufficient data to corroborate this.

On the basis of the cluster analysis, group A was subdivided into groups a1 and a2. However, these groups are not widely divergent and possibly originated from the same lineage. This idea is supported by the overlap of pathotypes within these groups; races 256 and 448 are present in both subgroups. In contrast, the subgroups b1 and b2 are more clearly defined, although races 0 and 392 are found in both. It is likely that race 0 from group b1 and race 0 from group b2 could be distinguished if the appropriate differential cultivars were available, because the AFLP haplotypes indicate that they are very distinct. Only one pathotype, 256, is shared by the two larger groups, A and B, since one isolate from Michoacán was shown to have this pathotype.

On the basis of the results of this study, we can tentatively relate haplotype groups with a particular pathotype group. For example, group A haplotypes are associated with pathotypes 448, 256, 320, and 1088; group b1 haplotypes with races 0 (b1), 384 and 392; and group b2 haplotypes with races 0 (b2), 8, 264, 256, and 392.

By extending the analysis to include $C$. lindemuthianum isolates from other regions of the country, we hope to further test the relationship between haplotype and pathotype groups. A method to predict the pathotype group of new isolates on the basis of the consensus AFLP haplotype data would greatly facilitate the analysis of $C$. lindemuthianum populations within Mexico and could be extended to include populations from other regions.

We conclude that the combined strategy of inoculating differential cultivars and using AFLP analysis is extremely efficient for the study of populations of $C$. lindemuthianum. The results obtained suggest that isolates of $C$. lindemuthianum can be separated into genetic lineages on the basis of AFLP data and that groups of haplotypes can be correlated to pathotype groups.

\section{ACKNOWLEDGMENTS}

We are grateful to L. Herrera-Estrella and A. Herrera-Estrella for critical reading of the manuscript and to our collaborators at the Université de Paris Sud, M. Dron and C. Neema, for helpful discussions and for providing unpublished data. We are indebted to CONACyT Mexico for support under grant $3218 \mathrm{~N}$ and to the EEC for grant CT1*-CT94-0074.

\section{LITERATURE CITED}

1. Efron, B., and Tibshirani, R. J. 1993. An Introduction to the Bootstrap. 1st ed. Chapman and Hall, New York.

2. Fabre, J.-V., Julien, J., Parisot, D., and Dron, M. 1995. Analysis of diverse isolates of Colletotrichum lindemuthianum infecting common bean using molecular markers. Mycol. Res. 99:429-435.

3. Fouilloux, G. 1976. Bean anthracnose: New genes of resistance. Annu. Rep. Bean Improv. Coop. 19:36-37.
4. Garrido-Ramirez, E. R., and Romero-Cova, S. 1989. Identificación de razas de Colletotrichum lindemuthianum (Sacc. y Magn.) Scrib. en México y busqueda de resistencia genetica a este hongo. Agrociencia 77: 139-156.

5. Hill, M., Witsenboer, H., Zabeau, M., Vos, P., Kesseli, R., and Michelmore, R. 1996. PCR-based fingerprinting using AFLP's as a tool for studying genetic relationships in Lactuca spp. Theor. Appl. Genet. 93: 1202-1210.

6. Janssen, P., Coopman, R., Huys, G., Swings, J., Bleeker, M., Vos, P., Zabeau, M., and Keraters, K. 1996. Evaluation of the DNA fingerprinting method AFLP as a new tool in bacterial taxonomy. Microbiology 142: 1881-1893.

7. Koenig, R., and Gepts, P. 1989. Allozyme diversity in wild Phaseolus vulgaris: Further evidence for two major centers of genetic diversity. Theor. Appl. Genet. 78:809-817.

8. Levy, M., Correa-Victoria, F. J., Zeigler, R. S., Xu, S., and Hamer, J. E. 1993. Genetic diversity of the rice blast fungus in a disease nursery in Colombia. Phytopathology 83:1427-1433.

9. Majer, D., Mithen, R., Lewis, B. G., Vos, P., and Oliver, R. P. 1996. The use of AFLP fingerprinting for the detection of genetic variation in fungi. Mycol. Res. 100:1107-1111.

10. Mastenbroek, C. 1960. A breeding program for resistance to anthracnose in dry shell haricot beans, based on a new gene. Euphytica 9:177-184.

11. Pastor-Corrales, M. A. 1991. Estandarización de variedades diferenciales y designación de razas de Colletotrichum lindemuthianum. (Abstr.) Phytopathology 81:694.

12. Pastor-Corrales, M. A., Erazo, O. A., Estrada, E. I., and Singh, S. P. 1994. Inheritance of anthracnose resistance in common bean accession G 2333. Plant Dis. 78:959-962.

13. Pastor-Corrales, M. A., Otoya, M. M., Molina, A., and Singh, S. P. 1995. Resistance to Colletotrichum lindemuthianum isolates from Middle America and Andean South America in different common bean races. Plant Dis. 79:63-67.

14. Raeder, U., and Broda, P. 1985. Rapid preparation of DNA from filamentous fungi. Lett. Appl. Microbiol. 1:17-20.

15. Sicard, D., Michalakis, Y., Dron, M., and Neema, C. 1997 Genetic diversity and pathogenic variation of Colletotrichum lindemuthianum in the three centers of diversity of its host, Phaseolus vulgaris. Phytopathology 87: 807-813.

16. Skroch, P., Tivang, J., and Nienhuis, J. 1992. Analysis of genetic relationships using RAPD marker data. Pages 26-29 in: Applications of RAPD Technology to Plant Breeding. Joint Plant Breeding Symposia Series. Crop Science Society of America, American Society for Horticultural Science, and American Genetic Association, Madison, WI.

17. Sokal, R. R., and Michener, C. D. 1958. A statistical method for evaluating systematic relationships. Univ. Kans. Sci. Bull. 37:1409-1438.

18. Spooner, D. M., Tivang, J., Nienhuis, J., Miller, J. T., Douches, D. S., and Contreras-M., A. 1996. Comparison of four molecular markers in measuring relationships among the wild potato relatives Solanum section Etuberosum (subgenus Potatoe). Theor. Appl. Genet. 92:532-540.

19. Vos, P., Hogers, R., Bleeker, M., Reijans, M., Van de Lee, T., Hornes, M., Frijters, A., Pot, J., Peleman, J., Kuiper, M., and Zabeau, M. 1995. AFLP: A new technique for DNA fingerprinting. Nucleic Acids Res. 23: 4407-4414.

20. Welsh, J., and McClelland, M. 1990. Finger printing genomes using PCR with arbitrary primers. Nucleic Acids Res. 18:7213-7218.

21. Williams, J. G. K., Kubelik, A. R., Livak, K. J., Rafalski, J. A., and Tingey, S. V. 1990. DNA polymorphisms amplified by arbitrary primers are useful as genetic markers. Nucleic Acids Res. 18:6531-6535.

22. Yerkes, W. D. 1958. Additional new races of Colletotrichum lindemuthianum in Mexico. Plant Dis. Rep. 42:329.

23. Yerkes, W. D., and Teliz-Ortiz, M. 1956. New races of Colletotrichum lindemuthianum in Mexico. Phytopathology 46:564-567.

24. Young, R. A., and Kelly, J. D. 1996. Characterization of the genetic resistance to Colletotrichum lindemuthianum in common bean differential cultivars. Plant Dis. 80:650-654.

25. Ziegler, R. S., Cuoc, L. X., Scott, R. P., Bernardo, M. A., Chen, D. H., Valent, B., and Nelson, R. J. 1995. The relationship between lineage and virulence in Pyricularia grisea in the Philippines. Phytopathology 85: 443-451. 